\title{
Penile schwannoma- case report \& review of literature
}

\author{
Mondal I ${ }^{1}$, Chaudhuri $\mathrm{A}^{2}$, Mangal $\mathrm{S}^{3}, \mathrm{Nag} \mathrm{D}^{4}$ \\ ${ }^{1}$ Dr. Ira Mondal, Junior Resident, ${ }^{2}$ Dr. Arnab Chaudhuri, Medical Officer, ${ }^{3}$ Dr. Sristidhar Mangal, Associate Professor, \\ ${ }^{4}$ Dr. Dipanwita Nag, Professor, all authors are affiliated with Department of Pathology, Medical College, Kolkata, The \\ West Bengal University of Health Sciences, Kolkata, West Bengal, India.
}

Address for Correspondence: Dr. Arnab Chaudhuri; E-mail: dr.arnab1234@gmail.com

\begin{abstract}
Schwannomas of the penis are extremely rare. Only very few cases were reported previously in English-language literature. We are presenting a case of a 62-year-old man with a $3 \times 2 \mathrm{~cm}$, slowly growing, painless tumor on the dorsal penile shaft without any other symptoms. Histopathological examination of the excised tumor revealed benign schwannoma and diagnosis was confirmed by immunohistochemistry S-100 protein. We also reviewed previously published articles on penile schwannoma to get a comprehensive picture.
\end{abstract}

Key-words: Schwannoma, penis, S-100 protein, immunohistochemistry.

\section{Introduction}

Schwannoma is a neoplasm, originating from the Schwann cells of the neurons, which may occur in any region of the body, but is very rare in the penis. To our knowledge, only few cases of penile schwannomas have been reported previously in the literature. Because of their rarity and non-specific presentations, misdiagnoses are common. [1]. In this article we have reported a case of a penile schwannoma. Its clinical manifestation, histopathological diagnosis and immunohistological findings have also been discussed. Further we reviewed the previously published cases of penile schwannomas and gave an outline regarding differential diagnosis and management. Although this condition is an extreme rarity, a diagnosis of schwannoma must be kept in mind while dealing with a penile neoplasm.

\section{Case History}

A 62-year-old man presented with a painless penile tumor, which had enlarged slowly during the last 2-3 years. Physical examination revealed a nontender, $3 \times 2 \mathrm{~cm}$ nodule on the dorsal aspect of the penile shaft near prepuce.

Overlying skin was intact. Blood test and other investigations were within normal limit.

The patient was operated under local anaesthesia. Circumcision operation was done along with removal of the tumor. Grossly, the tumor was a skin covered well-defined globular structure, measuring $2 \times 1.5 \times 1 \mathrm{~cm}^{3}$ (Fig.1A).

Microscopically, it was a mixture of a cellular component (Antoni A areas) and a loose myxoid component (Antoni B areas) (Fig. 1B, 1C). The Antoni A areas were composed of compact spindle cells arranged in fascicles or whorls with prominent nuclear palisading.

The Antoni B areas contained loosely and haphazardly arranged spindle cells in a myxoid stroma. Verrocay bodies were also noted. The tumor cells had no prominent nuclear pleomorphism. No mitotic figure was found. Immunohistochemically, S-100 protein was strongly expressed by most of the tumor cells (Fig.1D).

Manuscript received: $28^{\text {th }}$ April 2017

Reviewed: $8^{\text {th }}$ May 2017

Author Corrected: $17^{\text {th }}$ May 2017

Accepted for Publication: $24^{\text {th }}$ May 2017 
Case Report

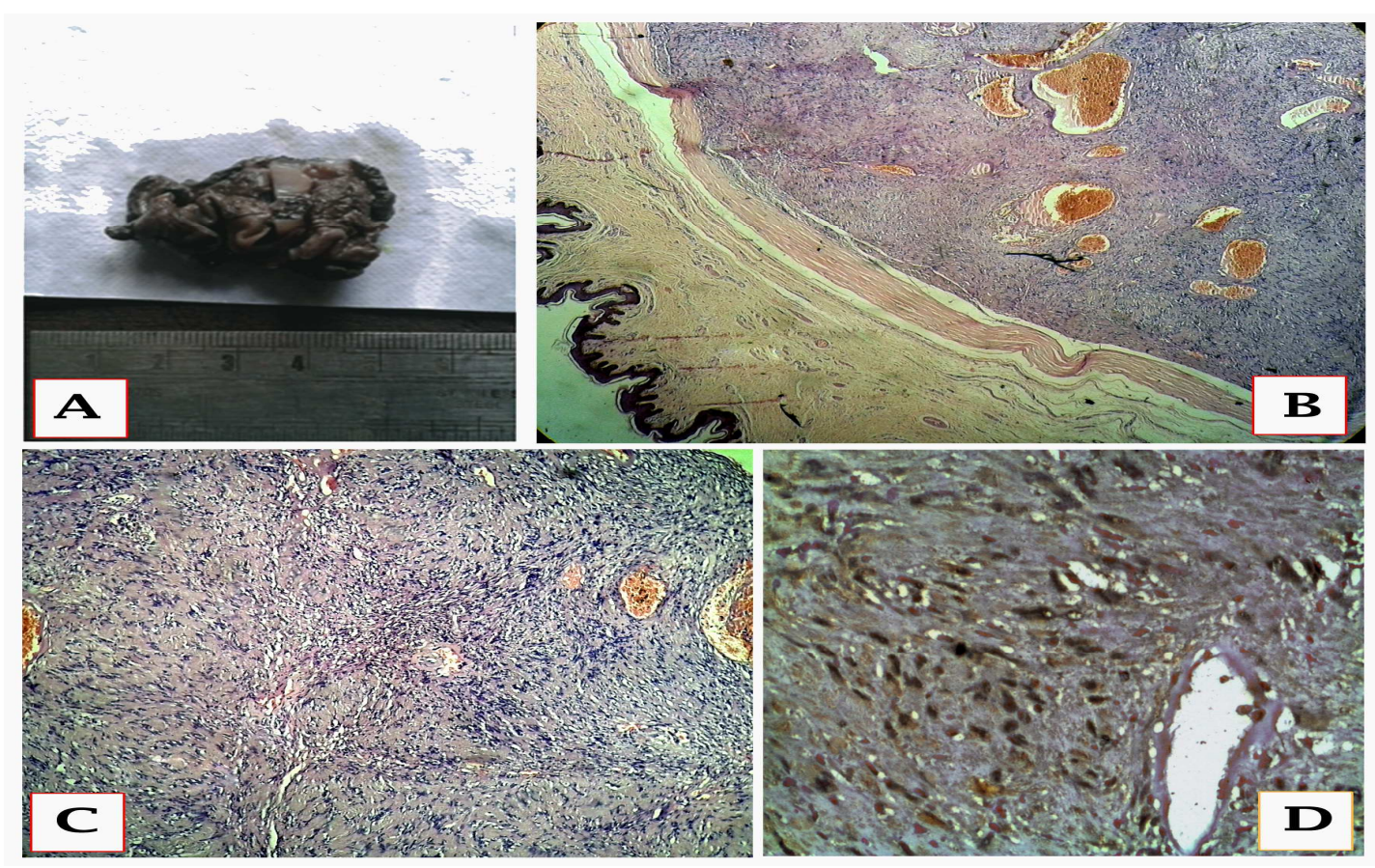

Fig-1A: circumcision specimen showing partially skin covered globular tumor mass. 1B- encapsulated tumor mass below epidermis (H \& Ex40). 1C- tumor composed of hypercellular Antoni A and myxoid hypocellular Antoni B. Verrocay bodies are noted (H \& Ex100). 1D- IHC showing S-100 positivity.

\section{Discussion}

Schwannomas are benign encapsulated nerve sheath tumors. Common locations of schwannomas include the head, neck and flexor surfaces of the upper and lower extremities. They grow slowly; Schwannomas are usually present for years before diagnosis. Pain and neurological symptoms are uncommon unless the tumor becomes large [2].

Histopathologically, the hallmark of a schwannoma is the biphasic pattern of Antoni A and Antoni B areas. Antoni A areas are composed of compact spindle cells with indistinct cytoplasmic borders arranged in short bundles or interlacing fascicles, with nuclear palisading being a common feature.

Antoni B areas are characterized by loosely and haphazardly arranged spindle cells in a myxoid stroma. Some schwannomas have nuclear atypia due to degenerative changes, but mitotic figures are rare [2].

Despite the rich innervations of the genital area, penile schwannomas are extremely rare. Dehner and Smith reported the first three cases of penile schwannomas in 1970 [3]. To the best of our knowledge, only 19 cases of penile schwannomas have been reported in the English-language literature [3-10]. The tumor occurred in the dorsal penile shaft in 10 cases and in the prepuce or in the glans in other cases [3-10]. In our case also the tumor was present at dorsal penile shaft. Of the 19 cases, 14 were a single occurrence and five were multiple occurrences [3-10]. Our case was also a single tumor. Histopathologic examination demonstrated malignant schwannoma in five patients, of whom three had von Recklinghausen disease, while no patient with benign tumor had such a hereditary disease $[3,6]$. Multiplicity was not related to malignancy [6]. Our patient also presented with benign lesion, not associated with any hereditary disease.

Despite its extreme rarity, a schwannoma should be included in the differential diagnoses of a penile tumor. Similar to schwannomas at other sites, penile schwannomas are mostly sporadic tumors occurring in patients without neurofibromatosis. The dorsal penile shaft is the most common location [6]. Unlike schwannomas at other locations, which mostly present as a single tumor, up to $30 \%$ of penile schwannomas occur as multiple tumors [3-10].

The differential diagnosis of superficial tumor in the penis should include lipoma, atheroma, fibroma, Peyronie's disease, fibrosis from autoinjection, and schwannoma [3]. In the literature, most penile schwannomas are located at the dorsum of the penis in 
the Buck's fascia, which is not characteristic of Peyronie's disease or injection related fibrosis [3,11]. Lipoma and atheroma can be differentiated from penile schwannoma because the former are softer and more superficial [11]. In addition to excision biopsy of the tumor, imaging studies, such as ultrasonography and magnetic resonance imaging, can be informative diagnostic modalities.

\section{Conclusion}

Schwannomas of the penis are extremely rare but should be included in the differential diagnosis for solid penile tumors. Because most penile schwannomas are benign, surgical excision is recommended only if the tumor causes pain or is growing rapidly. Malignant tumors are often associated with hereditary disease like von Recklinghausen disease. More cases and studies are required to further clarify the clinical characteristics of these tumors.

Key Messages: Schwannomas of the penis are extremely rare. In our case report a 62 year male patient presented with painless slow growing mass in penile shaft. Histopathologically it was diagnosed as benign schwannoma of penis and confirmed by positive S100 protein immunohistochemistry.

Funding: Nil, Conflict of interest: None initiated, Permission from IRB: Yes

\section{References}

1. Jiang R, Chen JH, Chen M, Li QM. Male genital schwannoma, review of 5 cases. Asian J Androl. 2003 Sep; 5 (3):251-4.

2. Weiss SW, Goldblum JR. Benign tumors of peripheral nerves. In: Weiss SW, Goldblum JR, editors. Enzinger and Weiss's Soft Tissue Tumors. 4th ed. St. Louis: Mosby; 2001.p.1146-73.
3. Dehner LP, Smith BH. Soft tissue tumors of the penis. A clinicopathologic study of 46 cases. Cancer. 1970 Jun; 25(6):1431-47.

4. Yeh CJ, Chuang WY, Huang ST, Jung SM. Schwannoma of the penis: a report of two cases. Chang Gung Med J. 2007 Nov-Dec; 30(6):555-9.

5. Pandit SK, Rattan KN, Gupta U, Budhiraja S, Singh Y, Sen J, Sen R. Multiple neurilemmomas of the penis. Pediatr Surg Int. 2000;16(5-6):457.

6. Sato D, Kase T, Tajima M, Sawamura Y, Matsushima M, Wakayama M, Kuwajima A. Penile schwannoma. Int J Urol. 2001 Feb; 8(2):87-9.

7. Andreas L, Tiemo K, Justus GM, Hubertus R, et al.Solitary Schwannoma of the Glans Penis. Urology. 2007 Nov; 70(5):1007.e5-e6. DOI: http://dx.doi. org/ 10.1016/j. urology.2007.08.004

8. Algaba F, Chivite A, Rodriguez-Villalba R, Sarquella J, Martinez-Montelongo R, Ruiz-Castane E. Schwannoma of the penis: a report of 2 cases. J Androl. 2003 Sep-Oct; 24(5):651-2. DOI: 10.1002/j.1939-4640. 2003. tb02722.x

9. Jung DC, Hwang SI, Jung SI, Kim SH, Kim SH. Neurilemmoma of the glans penis: ultrasonography and magnetic resonance imaging findings. J Comput Assist Tomogr. 2006 Jan-Feb;30(1):68-9.

10. Kumar GP, Sukumar S, Bhat SH, Nambiar A. Schwannoma of the penis: a common tumour at a rare site. Scand J Urol Nephrol. 2006;40(2):166-7.

11. Mayersak JS, Viviano CJ, Barbiarz JW. Schwannoma of the penis. J Urol. 1995 June; 15 (6): 1931-2. DOI: http://dx.doi.org/10. 1016/ S0022-5347 (01)67359-2.

\section{How to cite this article?}

Mondal I, Chaudhuri A, Mangal S, Nag D. Penile schwannoma- case report \& review of literature. Trop J Path Micro 2017;3(2):136-138.doi: 10.17511/jopm.2017.i2.11. 